\title{
The global land shortwave cryosphere radiative effect during the MODIS era
}

\author{
D. Singh, M. G. Flanner, and J. Perket \\ Climate and Space Sciences and Engineering, Ann Arbor, Michigan, USA \\ Correspondence to: D. Singh (sdeepak@umich.edu)
}

Received: 17 June 2015 - Published in The Cryosphere Discuss.: 28 July 2015

Revised: 28 October 2015 - Accepted: 3 November 2015 - Published: 10 November 2015

\begin{abstract}
The shortwave cryosphere radiative effect (CrRE) is the instantaneous influence of snow and ice cover on Earth's top-of-atmosphere (TOA) solar energy budget. Here, we apply measurements from the MODerate resolution Imaging Spectroradiometer (MODIS), combined with microwave retrievals of snow presence and radiative kernels produced from four different models, to derive CrRE over global land during 2001-2013. We estimate global annualmean land CrRE during this period of $-2.6 \mathrm{~W} \mathrm{~m}^{-2}$, with variations from -2.2 to $-3.0 \mathrm{~W} \mathrm{~m}^{-2}$ resulting from use of different kernels and variations of -2.4 to $-2.6 \mathrm{~W} \mathrm{~m}^{-2}$ resulting from different algorithmic determinations of snow presence and surface albedo. Slightly more than half of the global land CrRE originates from perennial snow on Antarctica, whereas the majority of the northern hemispheric effect originates from seasonal snow. Consequently, the northern hemispheric land CrRE peaks at $-6.0 \mathrm{~W} \mathrm{~m}^{-2}$ in April, whereas the southern hemispheric effect more closely follows the austral insolation cycle, peaking at $-9.0 \mathrm{~W} \mathrm{~m}^{-2}$ in December. Mountain glaciers resolved in $0.05^{\circ} \mathrm{MODIS}$ data contribute about $-0.037 \mathrm{~W} \mathrm{~m}^{-2}(1.4 \%)$ of the global effect, with the majority (94\%) of this contribution originating from the Himalayas. Interannual trends in the global annual-mean land CrRE are not statistically significant during the MODIS era, but trends are positive (less negative) over large areas of northern Asia, especially during spring, and slightly negative over Antarctica, possibly due to increased snowfall. During a common overlap period of 2001-2008, our MODIS estimates of the northern hemispheric land CrRE are about $18 \%$ smaller (less negative) than previous estimates derived from coarse-resolution AVHRR data, though interannual variations are well correlated $(r=0.78)$, indicating that these data are useful in determining longer-term trends in land CrRE.
\end{abstract}

\section{Introduction}

Snow- and ice-covered surfaces are the most reflective regions on Earth, and their extent can change substantially with small changes in climate. The presence of Earth's cryosphere greatly alters the planet's albedo and changes in cryospheric extent and reflectivity therefore partially determine the sensitivity of climate to anthropogenic and external forcings. After water-vapor and cloud feedback, the albedo feedback is the third most powerful positive feedback mechanisms operating within the current climate system (e.g., Bony et al., 2006; Winton, 2006; Randall et al., 2007; Soden et al., 2008; Shell et al., 2008; Flato et al., 2013).

Earth's cryosphere has shown compelling indications of climate change during recent decades, including mass loss from ice sheets and glaciers (e.g., Rignot et al., 2011; Gardner et al., 2013), rapid ablation of autumn Arctic sea ice (e.g., Serreze et al., 2007; Stroeve et al., 2014) and reduced seasonal snow coverage (e.g., Dery and Brown, 2007; Brown and Robinson, 2011). The Arctic is one of the most sensitive regions on Earth to global climate change (Manabe et al., 1992; Manabe and Stouffer, 1994; Miller and Russell, 2000; Meehl and Washington, 1990). Several recent studies (e.g., Chapman and Walsh, 2007; Monaghan et al., 2008; Steig et al., 2009) have shown that climate is also warming over west Antarctica and is related to Pacific Ocean warming (Ding et al., 2011) and circumpolar winds.

The shortwave cryosphere radiative effect (CrRE) is the instantaneous influence of snow and ice cover on Earth's top-of-atmosphere (TOA) solar energy budget (Flanner et al., 2011; Hudson, 2011; Perket et al., 2014). CrRE depends not only on snow and sea-ice coverage but also on local insolation, cloud cover and properties of the snow, ice and their underlying surface that determine reflectance. These features 
determine the impacts of cryospheric presence on net TOA solar flux (e.g., Winton, 2006; Qu and Hall, 2005). Changes in the extent of seasonal snow cover and sea ice can drive large changes in CrRE on sub-decadal timescales, whereas the areal coverage of ice sheets and glaciers tend to evolve on much longer timescales. The presence of the cryosphere also perturbs Earth's long-wave energy budget, e.g., through changes in emissivity and surface temperature resulting from the insulating effect of snow and the change in surface elevation induced by ice sheets. This study, however, concentrates exclusively on the shortwave component of CrRE (hereafter referred to simply as CrRE).

Our work focuses on developing a global, gridded, timeresolved data set of the land-based CrRE, using modern remote sensing observation of surface albedo and snow presence combined with radiative kernels that provide TOA radiative impacts. Flanner et al. (2011) derived a 30-year record of the northern hemispheric CrRE from coarse-resolution determinations of snow-cover extent. Here we apply higherresolution, higher-quality remote sensing data from the MODerate resolution Imaging Spectroradiometer (MODIS) to derive global land-based CrRE over 2001-2013, helping inform on the utility of the longer-term record derived by Flanner et al. (2011) and broadening the scope of these estimates to include the Southern Hemisphere. We generate CrRE for both all-sky and clear-sky conditions to help assess the masking effect of clouds and atmospheric aerosols. We provide statistics including global, hemispheric, glaciated and non-glaciated land CrRE averages. We also perform multiple analyses to determine the sensitivity of our estimates to the use of different thresholds for snow-cover determinations, different climatologies for missing data and radiative kernels generated with different distributions of clouds. These sensitivity analyses help us identify the sources of uncertainty that have relatively high impact on CrRE. In this paper, we focus only on land-based CrRE and refer readers to other recent estimates of CrRE from Arctic sea ice (Pistone et al., 2014; Cao et al., 2015).

\section{Methods}

\subsection{Satellite data set used}

MODIS MCD43C 3 collection 5 surface-albedo data (e.g., Schaaf et al., 2002) and accompanying snow-coverage statistic (both provided at spatial resolution $0.05^{\circ} \times 0.05^{\circ}$ ) are the primary input data sets we use to generate land-based CrRE (LCrRE) at 16-day resolution. The snow presence parameter $(0-100 \%)$ is a measure of the fraction of native measurements within each 16-day period and each $0.05^{\circ}$ pixel in which the presence of snow was detected. We assume any pixel with snow coverage greater than 0 has a surface albedo that was affected by the presence of snow. We apply data with quality flag 4 and better to maximize the spatial and temporal coverage of albedo measurements. Missing data in this collection arise from cloud cover and absence of sunlight at high latitudes during winter. To derive a spatially and temporally continuous LCrRE record, we also apply snowcover information from the Near-real-time Ice and Snow Extent (NISE) data set (Nolin et al., 1998), as described in the next subsection. NISE provides daily binary snow cover at $25 \mathrm{~km}$ Equal-Area Scalable Earth Grid (EASE-Grid) spatial resolution, projected on a polar stereographic grid. Because it is determined from microwave remote sensing observations, it offers estimates of snow presence under all conditions, including environments with clouds and low illumination. Since these data sets have different spatial resolutions, the NISE data set has been remapped to the higher-resolution MODIS grid prior to analysis.

We use global gridded estimates of snow-free albedo derived from MODIS (Moody et al., 2008), also provided at 16-day and $0.05^{\circ}$ resolution, as a baseline for determining the surface-albedo contrast induced by snow. These data are climatological 16-day averages derived from 2000-2004 MODIS measurements.

\subsection{Global albedo climatology for filling missing data}

A 16-day global surface-albedo climatology with spatial resolution of $0.05^{\circ} \times 0.05^{\circ}$ is generated to fill any missing MODIS data points, using the following steps:

- Step 1: for each pixel and each 16-day period of the year, we take the average albedo over all the years (20012013) of MODIS data during periods with valid measurements and non-zero snow cover. Since this is a seasonally varying gridded climatology, it is primarily used to replace albedo of missing MODIS data in situations deemed to be snow covered in the NISE data set.

- Step 2: we take the annual mean of the albedo values generated from the previous step for each snow-covered unfilled pixel in step 1 . We only apply this average at locations and times when the climatology from step 1 does not provide valid data (e.g., at pixels and 16-day intervals that had substantial cloud cover during each of the 13 years of MODIS observations).

- Step 3: albedo values generated from the previous two steps are averaged spatially over all pixels within each land classification type defined in the MODIS MCD12C1 product using IGBP (Type 1) land cover classification. This procedure produces an annual-mean snow-covered albedo climatology by land classification (listed in Table A1) and is used to fill any remaining missing pixels unfilled by steps 1 and 2 .

$\mathrm{MCD} 12 \mathrm{C} 1$ provides the global dominant land cover types at $0.05^{\circ} \times 0.05^{\circ}$ spatial resolution. It is continuous and therefore completely eliminates the chance of having any missing pixels after applying step 3 . 
Although the snow-free surface-albedo data set is continuous, it is undefined in regions with large solar zenith angle or near-permanent snow cover. To define snow-free albedo in these regions, we apply annual averages of the snow-free albedo values for each pixel (similar to method applied in step 2).

The ice-free surface albedo for permanent glaciated areas (e.g., Greenland, Antarctica) is assumed to be 0.26 , an average value of snow-free albedo over barren land (Flanner et al., 2011). This assumption enables a rough estimate of the TOA impact associated with presence of the full ice sheets. While our estimates of absolute LCrRE in these regions are therefore subject to ambiguities (such as the type of vegetation that would thrive without the ice sheet), seasonal and interannual changes in glacier surface albedo, e.g., as caused by altered insolation, melt extent and snow metamorphic state, drive changes in LCrRE that are unaffected by this assumption, since the ice-free albedo is assumed to be static.

Considering the current bed topography, removal of the West Antarctic Ice Sheet would expose the open ocean (albedo 0.07). However, we still use barren land albedo because of several other uncertain effects that would occur in the event of total ice sheet ablation: e.g., isostatic rebound of land, sea-level rise, encroachment of vegetation over open land. Our objective is to quantify the instantaneous LCrRE and quantifying all the aforementioned uncertainties in this study are beyond the scope of this paper. We also note that the MODIS land mask applied in our study excludes ice shelves.

\subsection{Methodology}

Our interest lies in the change in solar energy reflected because of snow, and we therefore assume that measured albedo increase in the presence of snow, relative to the snow free state, is caused entirely by snow. Flanner et al. (2011) employed a definition of CrRE that utilizes snow-cover fraction in order to facilitate the use of snow extent data without coincident albedo measurements from several decades ago. Here we utilize a simpler definition that omits snowcover fraction, since we have direct measurements of surface albedo from MODIS. Using this approach, the mathematical framework to describe CrRE at time $t$ within a region $R$ that is composed of $N$ partially snow- or ice-covered grid-cells $i$ is

$\operatorname{CrRE}(t, R)=\frac{1}{A(R)} \sum_{i=1}^{N} \operatorname{Max}\left[\left(\alpha(t, i)-\alpha_{\text {snow-free }}(t, i)\right), 0\right] \frac{\partial F}{\partial \alpha}(t, i) A(i)$,

where $A$ is area, $\alpha-\alpha_{\text {snow-free }}$ is the albedo contrast $(\Delta \alpha)$ and $\partial F / \partial \alpha$ is the change in TOA net solar energy flux with changing surface albedo. The "Max" function is used to avoid any negative albedo contrast values. We determine $\partial F / \partial \alpha$ using radiative kernels that provide the instantaneous effect on TOA energy budget associated with small perturbations in surface albedo (e.g., Shell et al., 2008). This equation is only applied to grid cells where snow presence has been detected, and LCrRE is otherwise assumed to be 0 .

We created kernel data sets using the general framework of Perket et al. (2014), using the Community Atmosphere Model versions 4 and 5 (CAM4 and CAM5). TOA energy fluxes were calculated with and without surface-albedo perturbations every model time step for 1 year of simulation, and flux differences were then averaged into monthly resolved kernels. We also apply radiative kernels generated previously with the CAM3 model (Shell et al., 2008) and Geophysical Fluid Dynamics Laboratory Atmosphere Model (AM2) (Soden et al., 2008).

A graphical representation of the basic algorithm used in our analysis is shown in Fig. 1 and can be summarized as follows.

1. We first check for the presence of snow in a particular pixel using MODIS data. If snow was present at any time during the 16-day retrieval (snow flag $>0$ ) then the difference between actual (16-day) surface albedo and snow-free albedo is taken as the albedo contrast.

2. If MODIS data were missing then presence of snow is checked using NISE data. If snow is present during some or all of the 16-day period, then albedo contrast is determined by taking the difference between climatological snow-covered albedo for that grid cell (and time of year, as described in the previous subsection) and snow-free albedo. Since the NISE data set is continuous and daily resolved, we are able to determine those situations when a particular pixel was covered with snow for only a portion of the 16-day period of MODIS measurements. In those cases, if a pixel is covered with snow for $D$ days out of 16 , then the albedo contrast is multiplied with a scaling factor of $D / 16$.

3. If MODIS determines a pixel is not snow covered (snow flag $=0$ ) or in the absence of MODIS data if NISE does not indicate any snow $(D=0)$, then albedo contrast and LCrRE are set to 0 for that pixel.

4. After determining the albedo contrast, this term is multiplied with the various radiative kernels to derive different estimates of all-sky and clear-sky LCrRE. Except as noted in sensitivity studies described later, subsequent LCrRE results are derived from the CAM4 radiative kernel, which simulates an intermediate level of cloud masking compared with the other kernels. 


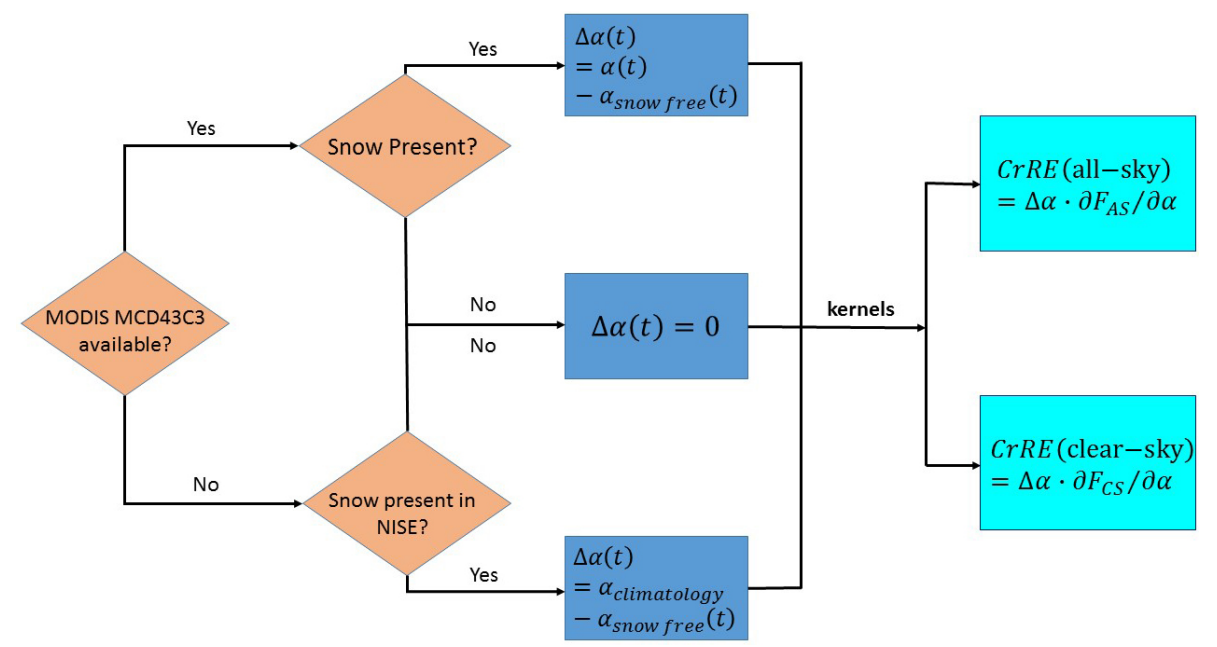

Figure 1. Algorithm for calculating CrRE.

\section{Results and discussion}

\subsection{Spatial and seasonal variability of the mean climate state}

All-sky global annual-mean LCrRE during 2001-2013 calculated using the CAM4 kernel is $-2.58 \mathrm{~W} \mathrm{~m}^{-2}$ and ranges from -2.16 to $-2.96 \mathrm{~W} \mathrm{~m}^{-2}$ with application of different radiative kernels. Table 1a shows LCrRE averages over different domains and calculated with different radiative kernels. Permanent glaciated regions (e.g., Greenland and Antarctica) contribute about two-thirds of the net global LCrRE due to their persistently high albedo around the year. For this discussion, land classified as snow or ice in the MODIS MCD12C1 land type data set (Appendix A) is considered as permanently glaciated.

Due to the size of the Antarctic Ice Sheet, the Southern Hemisphere contributes about $60 \%$ of the global LCrRE. However, non-glaciated regions in the Northern Hemisphere contribute about $32 \%$ of the global LCrRE. Because the areal extent of seasonal snow has little "memory" beyond a year, non-glaciated component of the LCrRE can respond rapidly to climate change and drive albedo feedback on sub-decadal timescales. The impact of non-glaciated region in the Southern Hemisphere is negligible because of less land presence at mid- and high latitudes (Fig. 2), contributing only about $0.08 \%$ of the global LCrRE. In the Northern Hemisphere, non-glaciated regions contribute about 3.7 times more to LCrRE than glaciated areas. LCrRE associated with permanent glacier cover in mountain regions (e.g., the Himalaya) is also clearly visible, even though they are situated at much lower latitudes (Fig. 2). Table $1 \mathrm{~b}$ and c show percentage contribution of different domains and separate land masses to the global LCrRE, respectively.

Clear-sky LCrRE values are expectedly higher than allsky LCrRE values because of the absence of cloud scatter-

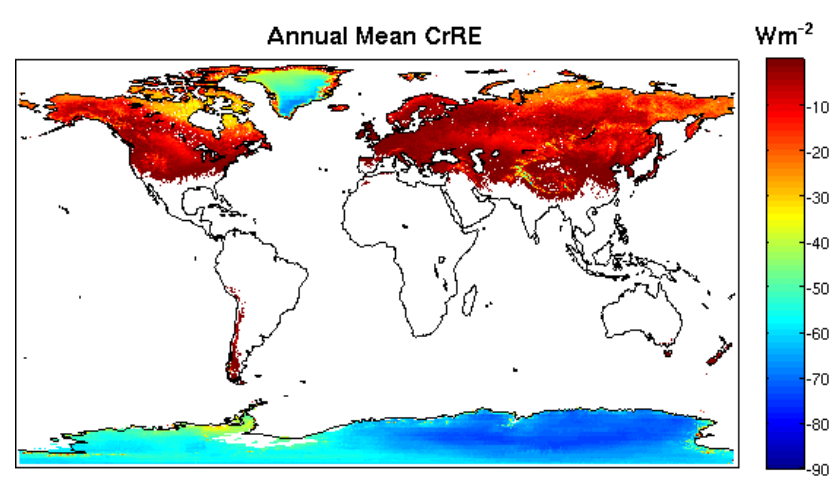

Figure 2. Map showing annual-mean all-sky land CrRE, averaged over 2001-2013, derived with the CAM4 kernel.

ing. Similarly, all-sky LCrRE derived from the CAM5 kernel is higher than that derived from the CAM4 kernel because cloud masking is substantially less in CAM5 due to the prevalence of thinner clouds (Kay et al., 2012; Perket et al., 2014). AM2 and CAM4 values are similar, indicating a similar degree of cloud masking in these two kernels, whereas the CAM3 kernel provides substantially greater attenuation of surface-albedo anomalies at the TOA (Flanner et al., 2011). Cao et al. (2015) determined that the CAM3 and AM2 radiative kernels likely mask too much of the Arctic sea-ice radiative effect, but it is unclear whether these kernel biases exist over land and have persisted in the more modern CAM4 and CAM5 models.

Figure 3 shows global and hemispheric monthly variations of LCrRE for both all-sky and clear-sky conditions. Seasonal variations are apparent in both hemispheres. LCrRE values peak (become most negative) during April in the Northern Hemisphere, about 2 months before the peak boreal solstice insolation. However, southern hemispheric LCrRE peaks in December during maximum austral insolation. These dif- 
Table 1. (a) All-sky (clear-sky) cryosphere radiative effect averaged over different domains and derived with various radiative kernels $\left(\mathrm{W} \mathrm{m}^{-2}\right.$ ). (b) Percentage contribution of different domains to the global LCrRE using CAM4 kernels. (c) Percentage contribution of different land masses to the global LCrRE using CAM4 kernels.

\begin{tabular}{|c|c|c|c|c|c|}
\hline (a) & & CAM4 kernel & CAM5 kernel & CAM3 kernel & AM2 kernel \\
\hline Northern & Glaciated & $-0.45(-0.62)$ & $-0.56(-0.63)$ & $-0.36(-0.61)$ & $-0.45(-0.60)$ \\
\hline Hemisphere & Non-glaciated & $-1.67(-2.4)$ & $-1.95(-2.48)$ & $-1.16(-2.42)$ & $-1.40(-2.24)$ \\
\hline Southern & Glaciated & $-3.08(-3.58)$ & $-3.41(-3.61)$ & $-2.79(-3.58)$ & $-3.16(-3.59)$ \\
\hline Hemisphere & Non-glaciated & $-0.004(-0.007)$ & $-0.005(-0.008)$ & $-0.003(-0.007)$ & $-0.004(-0.007)$ \\
\hline \multirow[t]{2}{*}{ Global } & Glaciated & $-1.77(-2.1)$ & $-1.99(-2.12)$ & $-1.58(-2.09)$ & $-1.81(-2.09)$ \\
\hline & Non-glaciated & $-0.84(-1.2)$ & $-0.98(-1.25)$ & $-0.58(-1.21)$ & $-0.70(-1.12)$ \\
\hline Global & Global & $-2.58(-3.28)$ & $-2.96(-3.37)$ & $-2.16(-3.31)$ & $-2.51(-3.22)$ \\
\hline \multirow[t]{2}{*}{ (b) } & & $\%$ & & & \\
\hline & & Contribution & & & \\
\hline Northern & Glaciated & $8.7(9.5)$ & & & \\
\hline Hemisphere & Non-glaciated & $32.4(36.6)$ & & & \\
\hline Southern & Glaciated & $59.7(54.6)$ & & & \\
\hline Hemisphere & Non-glaciated & $0.08(0.1)$ & & & \\
\hline \multirow[t]{2}{*}{ Global } & Glaciated & $68(64)$ & & & \\
\hline & Non-glaciated & $32(36)$ & & & \\
\hline Global & Global & $100(100)$ & & & \\
\hline \multirow[t]{2}{*}{ (c) Land mass } & LCrRE & $\%$ & & & \\
\hline & & Contribution & & & \\
\hline Antarctica & $-1.51(-1.76)$ & $58.6(53.6)$ & & & \\
\hline Europe + Asia & $-0.55(-0.79)$ & $21.1(23.94)$ & & & \\
\hline North America & $-0.34(-0.49)$ & $13.02(14.83)$ & & & \\
\hline Greenland & $-0.19(-0.25)$ & $7.2(7.5)$ & & & \\
\hline South America & $-0.0024(-0.0043)$ & $0.09(0.13)$ & & & \\
\hline Australia & $-2.28 \times 10^{-4}\left(-4.37 \times 10^{-4}\right)$ & $\sim 0$ & & & \\
\hline Africa & $-5.59 \times 10^{-5}\left(-6.2 \times 10^{-5}\right)$ & $\sim 0$ & & & \\
\hline Global & $-2.58(-3.28)$ & $100(100)$ & & & \\
\hline
\end{tabular}

ferences occur because the northern hemispheric LCrRE is dominated by seasonal snow, while southern hemispheric LCrRE is dominated by permanent glaciated Antarctica, and thus the seasonal cycle of LCrRE is determined more directly by insolation in the Southern Hemisphere. Spatial distributions of tri-monthly seasonal averages of LCrRE are shown in Fig. 4, indicating the same insolation-modulated tendencies over glaciated terrain described earlier. The timing of peak LCrRE in regions with seasonal snow, however, depends on the timing of melt onset, which almost always precedes the peak insolation period.

Peak LCrRE over glaciated regions of the Northern Hemisphere occurs in May, lagging the peak over non-glaciated regions by about one month (Fig. 5). Glaciated LCrRE in the Northern Hemisphere peaks before the summer solstice be- cause Greenland surface albedo decreases between May and the end of June as summer melt commences. This tendency is not apparent over Antarctica because a smaller portion of the Antarctic Ice Sheet experiences surface melt during summer. Also the LCrRE change is more gradual for glaciated than non-glaciated regions during both melting and freezing seasons. As the temperature rises, temporary snow over nonglaciated land ablates relatively quickly. This causes a rapid decrease in surface albedo and hence lowering of the albedo contrast. Similar observations cannot be made for the Southern Hemisphere due to negligible LCrRE contribution from non-glaciated region. Global LCrRE values show less seasonal variation than the hemispheric averages because they are basically averages of two hemispheric seasonal cycles that are somewhat out of phase with each other. Nonetheless, 


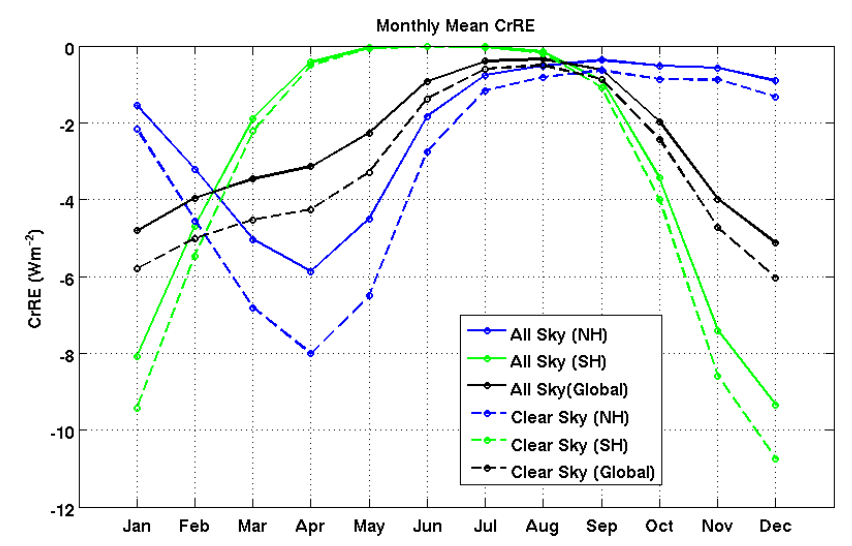

Figure 3. Annual cycle of hemispheric and global LCrRE for both all-sky and clear-sky conditions, derived from the CAM4 radiative kernels.

global LCrRE does exhibit a minimum during July and August, when there is little seasonal snow cover in the Northern Hemisphere and Antarctica receives little insolation.

We observe a contribution of about $-0.037 \mathrm{~W} \mathrm{~m}^{-2}$ ( $1.43 \%$ of the global total) from high mountainous regions (Himalayas, Andes, etc.) towards global LCrRE. The Himalayan region alone contributes about $93.8 \%$ of the total mountainous region LCrRE. (Here, we define the high mountainous contribution to LCrRE as that coming from permanent glaciated areas between latitudes of $60^{\circ} \mathrm{S}$ and $60^{\circ} \mathrm{N}$.) The contribution from these high-altitude areas is relatively smaller but consistent throughout the year. Our use of $0.05^{\circ}$ resolution data allows us to determine LCrRE over many regions with patchy snow extent, though mountain snow cover varies substantially on even smaller spatial scales. Figure 6 shows LCrRE contribution of the Andes and the Himalayas averaged over the MODIS era.

\subsection{Sensitivity analysis}

A sensitivity analysis of LCrRE has been done to estimate its dependence on various parameters included in the algorithm (Table 2). In this part of the study, CAM4 kernels are used and other parameters are varied. The first column represents the LCrRE values from the default case using the algorithm discussed in Sect. 2.3 (Fig. 1). The second column lists LCrRE values generated using only the NISE snow flag (i.e., snow presence is determined exclusively with NISE measurements rather than MODIS). Differences between these estimates are due to the different remote sensing techniques applied to determine snow presence and different spatial and temporal resolutions of the NISE and MODIS data sets.

The third and fourth columns are similar to the first and second columns, respectively, but apply the land class climatology of albedo contrast instead of spatially and temporally varying albedo contrast (Sect. 2.2). The derivation of these land class climatology values is described in step 3 of
Sect. 2.2. A list of mean albedo values and standard deviations for the different land classes is provided in Appendix A. In these cases land class climatology albedo values have been used irrespective of data availability in MODIS, in combination with snow presence determined from MODIS + NISE (column 3) and exclusively from NISE (column 4). This sensitivity study is designed to assess the utility of using much simpler estimates of snow-covered albedo than our more involved space- and time-dependent estimates.

LCrRE values in the second, third and fourth columns (Table 2) are very similar to each other. In all three cases the estimated LCrRE is lower than the original analysis (column 1). This indicates the dependence of LCrRE on MODIS snow flag and global albedo climatology, and changing either of those drops the LCrRE estimates by about $8 \%$ globally. Also, when land class climatological albedos are used, LCrRE is very similar for different choice of snow flags. This may be due to the fact that the land class climatology only depends on land class type and does not vary with time.

MODIS MCD43C 3 albedo data are accompanied by quality flags, indicating the fraction of input measurements to each 16-day data point that were made under cloud-free conditions with sufficiently small solar zenith angle (e.g., Schaaf et al., 2002). Table 3 shows a comparative study of LCrRE determined without quality flag filtering (i.e., quality flag 4 and better) and determined using only quality flag 2 or better albedo data. Quality flag 2 is mixed, with $75 \%$ or less of the underlying data derived from inverting reflectance for the BRDF retrievals and $25 \%$ or less of the underlying data filled. Using better albedo data (lower quality flag) does not make a significant difference in our determination of global LCrRE. This indicates that the fill values applied in the MCD43C3 retrieval algorithm are similar to our developed climatology (Sect. 2.2).

\subsection{Interannual trends}

Annual global LCrRE averages do not show significant interannual trends during the MODIS era (Fig. 7), perhaps partially due to the relatively short duration of this period. Slopes for global, northern hemispheric and southern hemispheric LCrRE are $-2 \times 10^{-3} \mathrm{~W} \mathrm{~m}^{-2} \mathrm{yr}^{-1}$, $-1.3 \times 10^{-3} \mathrm{~W} \mathrm{~m}^{-2} \mathrm{yr}^{-1}$ and $7.3 \times 10^{-4} \mathrm{~W} \mathrm{~m}^{-2} \mathrm{yr}^{-1}$, respectively. These trends are not significant at the $95 \%$ confidence level.

To better understand the LCrRE trend, pixel-by-pixel trend maps have been generated using the Mann-Kendall regression technique with $95 \%$ significance level (Fig. 8). A strong positive trend (indicating less negative LCrRE) is observed over some regions of the Northern Hemisphere, especially over northern Asia during the spring season (Fig. 8b). Positive trends over seasonally snow-covered areas are most likely due to a decrease in snow coverage (e.g., Qu and Hall, 2007; Vaughan et al., 2013), and the trend in LCrRE that we find over northern Asia is consistent with studies 

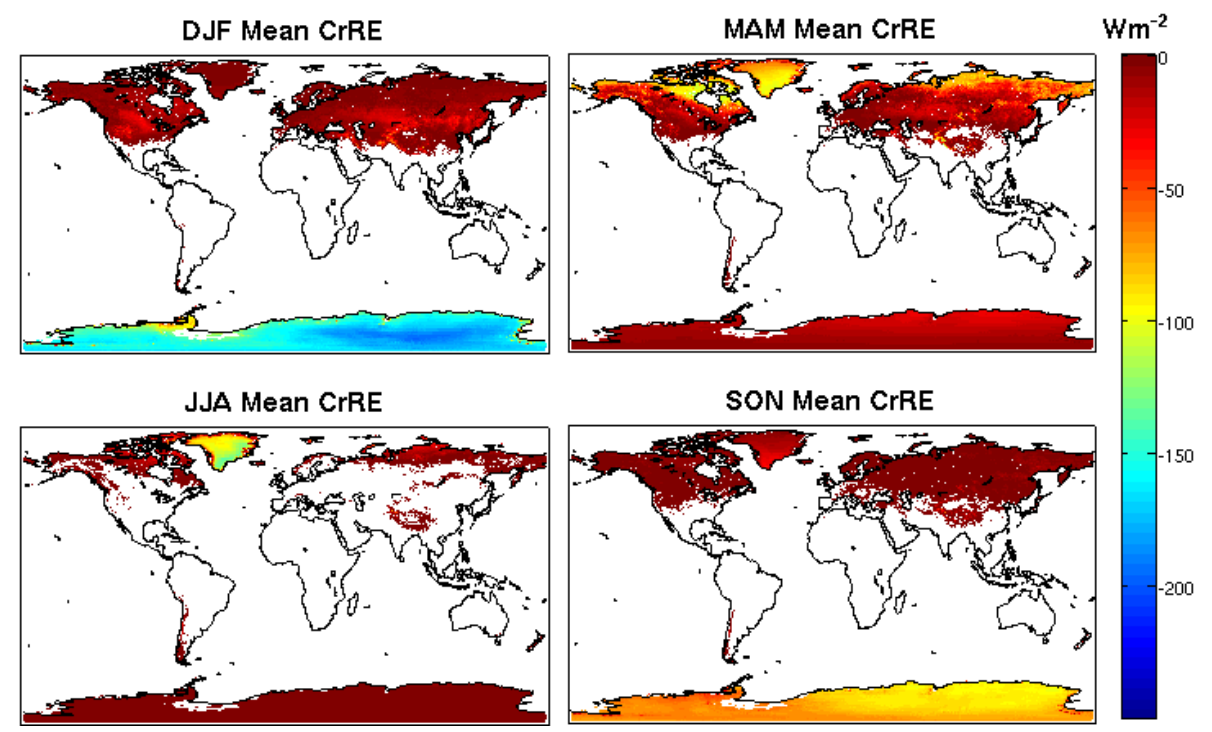

Figure 4. Tri-monthly seasonally averaged LCrRE derived with the CAM4 all-sky kernel (DJF - December, January, February; MAM March, April, May; JJA - June, July, August; SON - September, October, November).
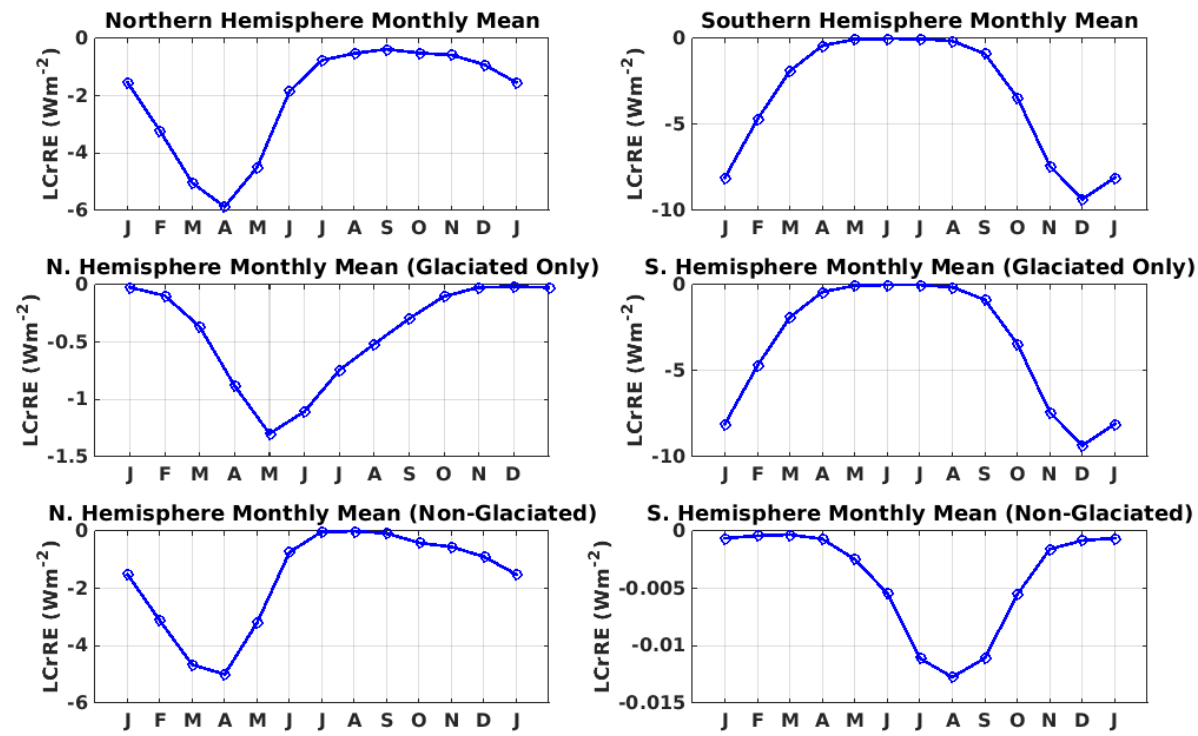

Figure 5. All-sky LCrRE averaged over the Northern (left panels) and Southern (right panels) Hemisphere, shown as contributions from all land within the hemisphere (top panels), permanently glaciated areas only (middle panels) and non-glaciated areas only (bottom panels). Data were derived with the CAM4 radiative kernel.

showing recent declines in snow cover over this region (e.g., Dery and Brown, 2007; Brown and Robinson, 2011; Derksen et al., 2014). Possible reasons for the positive trends seen over Greenland include (1) increased snow metamorphism and black carbon deposition (e.g., Box et al., 2012; Keegan et al., 2014); (2) transport and deposition of dust and other light-absorbing impurities over the ice sheets due to increased dust source areas associated with increased snowfree area (Dumont et al., 2014); (3) higher melt extent across the Greenland ice sheet expose more fresh water at the sur- face (Tedesco et al., 2014); and (4) MODIS sensor degradation on the Terra satellite during recent years (Sun et al., 2014; Lyapustin et al., 2014), which would indicate a spurious decline in albedo.

We also observe slightly negative LCrRE trends over Antarctica, which may be due to increases in snowfall that have decreased the duration that surface snow has to "age", thereby increasing surface albedo (Picard et al., 2012). Interestingly, LCrRE has also become more negative over some 

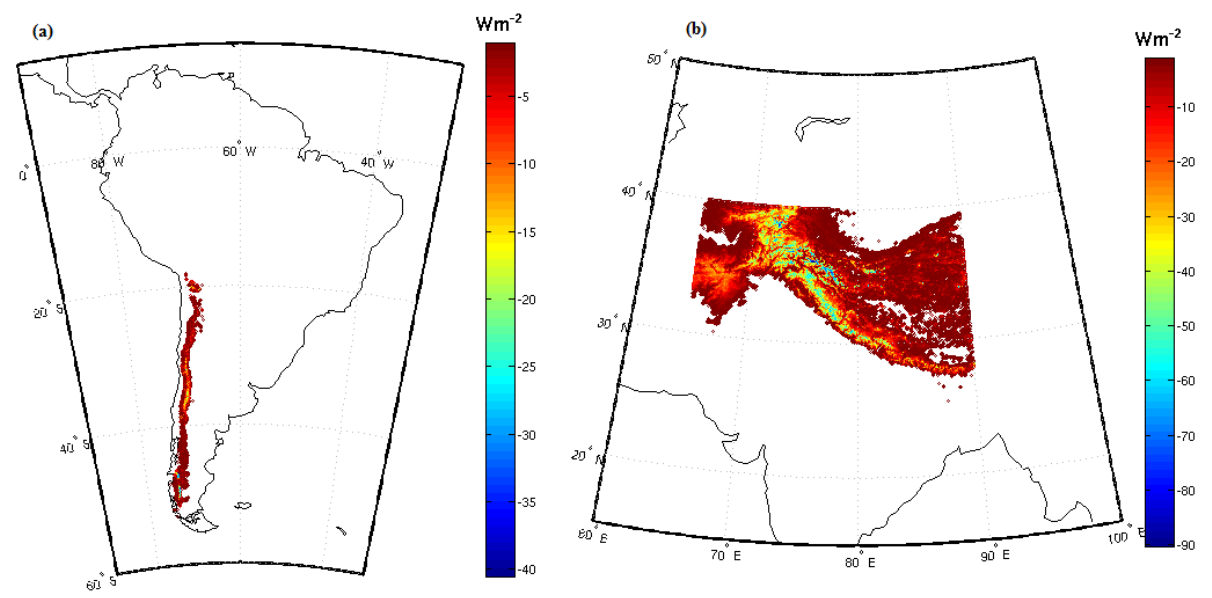

Figure 6. Maps showing all-sky LCrRE, averaged over 2001-2013 over the (a) Andes and (b) Himalayan mountain ranges.

Table 2. All-sky (clear-sky) CrRE ( $\mathrm{W} \mathrm{m}^{-2}$ ) derived with different algorithms. All cases apply the CAM4 radiative kernels.

\begin{tabular}{|c|c|c|c|c|c|}
\hline & & $\begin{array}{l}\text { Both flags } \\
\text { with original } \\
\text { climatology }\end{array}$ & $\begin{array}{l}\text { Only NISE } \\
\text { flag with } \\
\text { original } \\
\text { climatology }\end{array}$ & $\begin{array}{l}\text { Both flags } \\
\text { with land } \\
\text { class } \\
\text { climatology }\end{array}$ & $\begin{array}{l}\text { Only NISE } \\
\text { flag with } \\
\text { land class } \\
\text { climatology }\end{array}$ \\
\hline Northern & Glaciated & $-0.45(-0.62)$ & $-0.37(-0.51)$ & $-0.39(-0.54)$ & $-0.38(-0.51)$ \\
\hline Hemisphere & Non-glaciated & $-1.67(-2.4)$ & $-1.4(-2.0)$ & $-1.41(-2.05)$ & $-1.47(-2.1)$ \\
\hline Southern & Glaciated & $-3.08(-3.58)$ & $-3.03(-3.51)$ & $-2.91(-3.38)$ & $-2.91(-3.38)$ \\
\hline Hemisphere & Non-glaciated & $-0.004(-0.007)$ & $-0.004(-0.006)$ & $-0.005(-0.008)$ & $-0.008(-0.012)$ \\
\hline \multirow[t]{2}{*}{ Global } & Glaciated & $-1.77(-2.1)$ & $-1.7(-2.0)$ & $-1.65(-1.96)$ & $-1.65(-1.95)$ \\
\hline & Non-glaciated & $-0.84(-1.2)$ & $-0.7(-1.0)$ & $-0.71(-1.03)$ & $-0.74(-1.05)$ \\
\hline Global & Global & $-2.58(-3.28)$ & $-2.4(-3.01)$ & $-2.36(-2.99)$ & $-2.38(-3.0)$ \\
\hline
\end{tabular}

Table 3. All-sky (clear-sky) CrRE $\left(\mathrm{W} \mathrm{m}^{-2}\right)$ with different quality flag filters, derived using CAM4 kernels in all cases.

\begin{tabular}{llll}
\hline & & $\begin{array}{l}\text { Quality flag } \\
\text { 4 or better }\end{array}$ & $\begin{array}{l}\text { Quality flag } \\
\text { 2 or better }\end{array}$ \\
\hline Northern & Glaciated & $-0.45(-0.62)$ & $-0.43(-0.59)$ \\
Hemisphere & Non-glaciated & $-1.67(-2.4)$ & $-1.6(-2.29)$ \\
\hline Southern & Glaciated & $-3.08(-3.58)$ & $-3.07(-3.57)$ \\
Hemisphere & Non-glaciated & $-0.004(-0.007)$ & $-0.004(-0.006)$ \\
\hline Global & Glaciated & $-1.77(-2.1)$ & $-1.75(-2.08)$ \\
& Non-glaciated & $-0.84(-1.2)$ & $-0.8(-1.15)$ \\
\hline Global & Global & $-2.58(-3.28)$ & $-2.55(-3.23)$ \\
\hline
\end{tabular}

regions of Central Asia, presumably due to increased temporal coverage of snow.

\subsection{Comparison with previous study}

The current study and that of Flanner et al. (2011) have a common overlap period of 2001-2008. To compare the

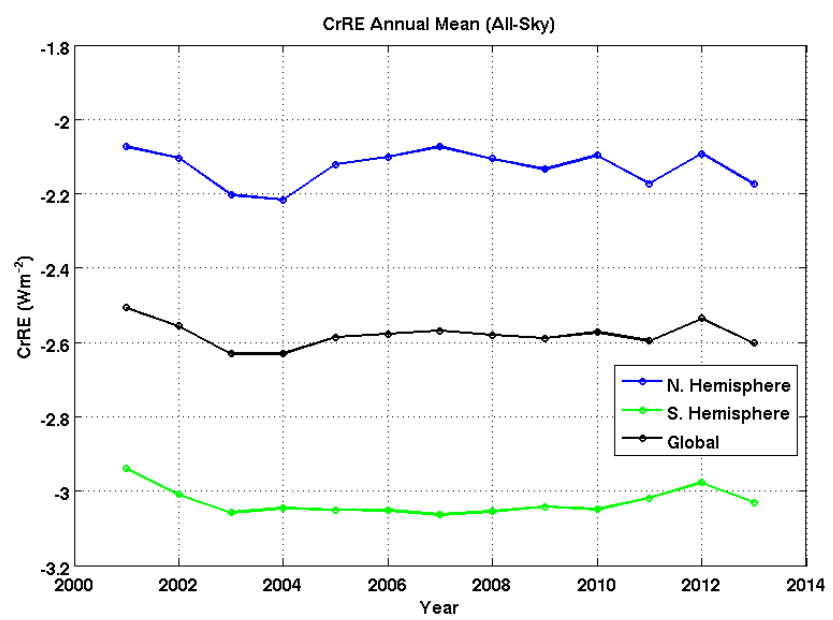

Figure 7. Annual-mean land LCrRE time series during 2001-2013 for the globe and each hemisphere. 

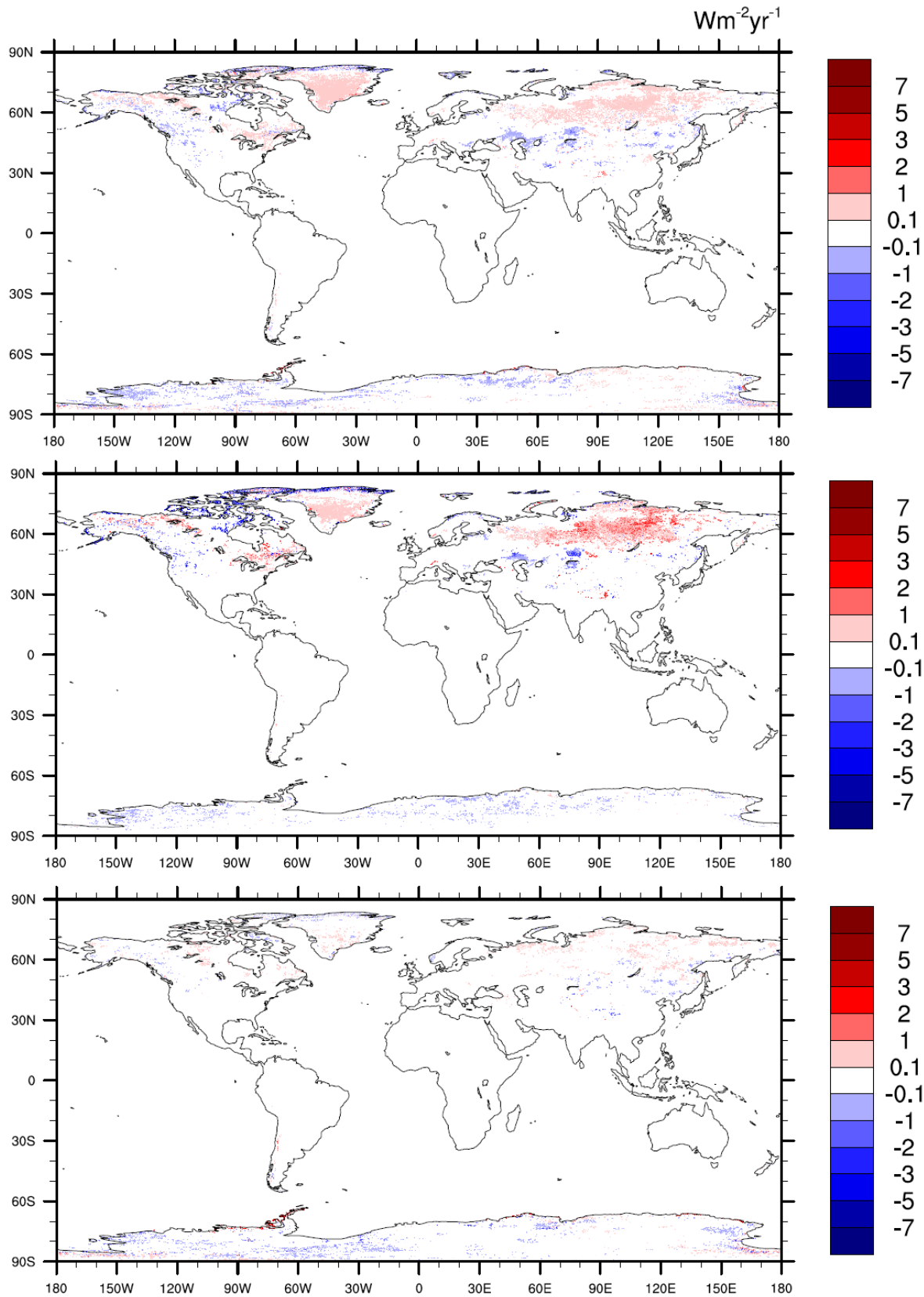

Figure 8. LCrRE trend maps for annual (top panel), MAM (middle panel) and SON (bottom panel) seasons (MAM - March, April, May; SON - September, October, November). Trends were derived using Mann-Kendall regression technique. Only regions with significant trends $(p=0.05)$ are shown in the map.

derivations of LCrRE between these two studies, we rederived northern hemispheric LCrRE during 2001-2008 using the CAM3 radiative kernel and an assumption of ice-free albedo over Greenland of 0.316, as in Flanner et al. (2011). For this overlap period, and using these assumptions, the current study gives a LCrRE value of about $-1.41 \mathrm{~W} \mathrm{~m}^{-2}$ over the Northern Hemisphere as compared to $-1.72 \mathrm{~W} \mathrm{~m}^{-2}$ from Flanner et al. (2011), who determined snow presence during 1979-2008 from coarse-resolution AVHRR data (e.g.,
Robinson and Frei, 2000). (The 1979-2008 mean northern hemispheric LCrRE found by Flanner et al. (2011) was $-2.0 \mathrm{~W} \mathrm{~m}^{-2}$, indicating less boreal cryospheric influence during 2001-2008 compared with 1979-2001.) To understand this difference, an LCrRE difference map between the current study and Flanner et al. (2011) has been generated (Fig. 9). This difference was taken between annual-mean LCrRE values over the common overlap period. We find that the use of coarse-resolution snow-cover data (Flanner 


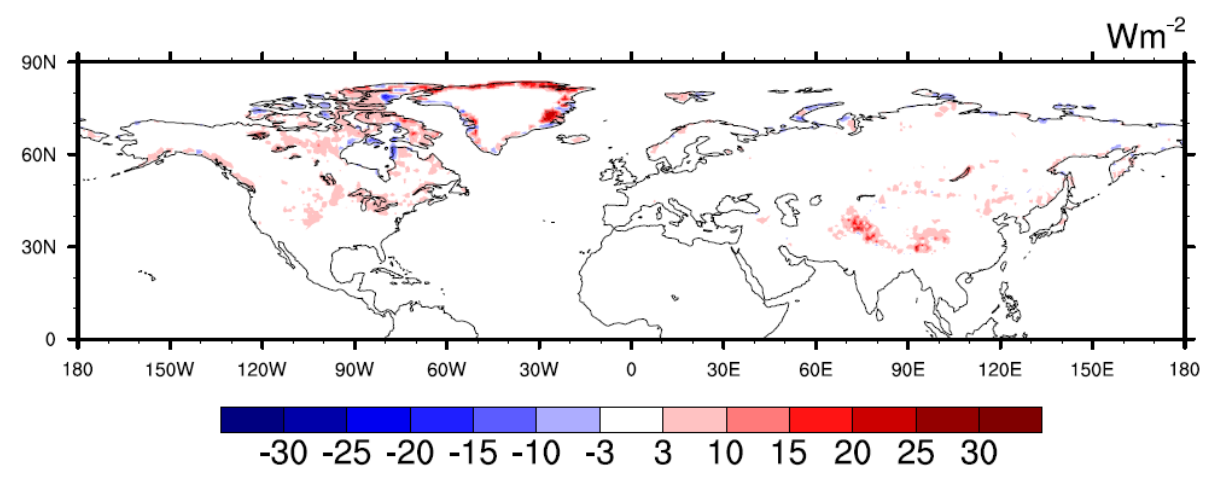

Figure 9. Difference of 2001-2008 mean LCrRE between the current study and Flanner et al. (2011) using CAM3 kernels. Areas of red indicate a stronger (more negative) LCrRE determined by Flanner et al. (2011) than determined here.

et al., 2011) likely leads to overestimation of LCrRE along the continental edges and in mountainous regions like the Himalayas. Some of the differences along the continental edges (especially of Greenland), depicted in Fig. 9 at $1^{\circ}$ resolution, are likely due to poor resolution of land cover fraction in the AVHRR snow-cover data used by Flanner et al. (2011), and possibly also the influence of land-fast sea ice. Snow in mountainous regions is difficult to resolve in any model because of irregular topography and is uncertain in both data sets. The annual-mean LCrRE time series (Fig. 10) of both data sets show similar patterns and exhibit a correlation coefficient of 0.78 , lending confidence in the application of longer-term AVHRR data to derive estimates of large-scale LCrRE trends. We expect that the current analysis will be useful in determining correction algorithms for biases in the Himalayas and along the coastal margins of Greenland that may result from use of coarse-resolution AVHRR data.

\section{Conclusions}

We have estimated a global land-based CrRE (LCrRE) of about $-2.6 \mathrm{~W} \mathrm{~m}^{-2}$ during 2001-2013, with about $59 \%$ of the effect originating from Antarctica. For a particular region, LCrRE can vary significantly (e.g., from 0 to $-250 \mathrm{~W} \mathrm{~m}^{-2}$ over Antarctica; Fig. 5) depending on the season. Due to a large contribution from seasonal snow, northern hemispheric LCrRE peaks during April, whereas southern hemispheric LCrRE peaks during the December solstice. About $78 \%$ of northern hemispheric LCrRE originates from seasonal or non-glaciated snow while about $99.9 \%$ of southern hemispheric LCrRE comes from glaciated areas. Mountainous region provide a small $\left(-0.037 \mathrm{~W} \mathrm{~m}^{-2}\right)$ yet consistent contribution towards LCrRE throughout the year. Higherresolution data have improved the LCrRE estimates relative to previous studies by better resolving the snow impact in mountainous regions and in coastal areas, leading to a $18 \%$ smaller estimate of northern hemispheric LCrRE during 2001-2008 in this study than in Flanner et al. (2011). In-

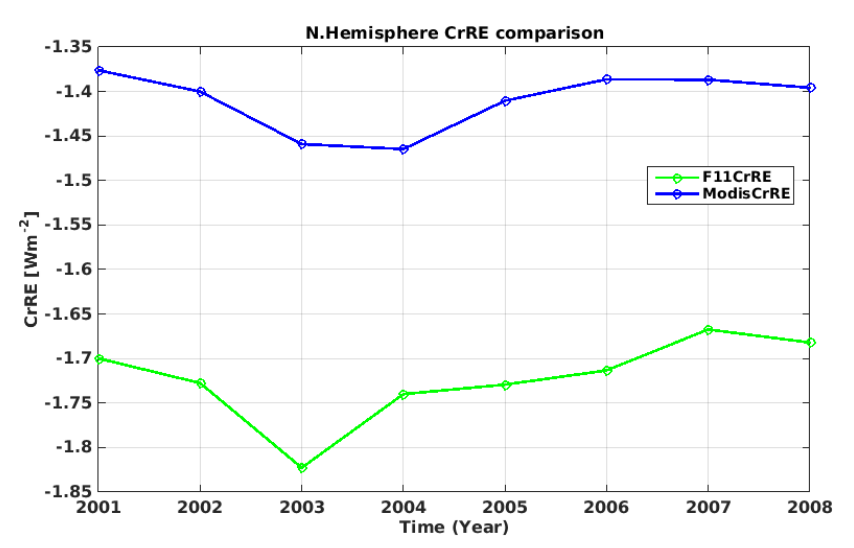

Figure 10. Annual-mean northern hemispheric LCrRE time series derived for the current study (ModisCrRE) and by Flanner et al. (2011) (F11CrRE) using CAM3 kernels.

terannual variations between these two studies are well correlated $(r=0.78)$, indicating that these data are useful in determining longer-term trends in LCrRE.

Snow cover, however, is patchy on substantially smaller spatial scales than the $0.05^{\circ}$-resolution analysis applied here. No significant trend over time has been observed in global annual LCrRE values between 2001 and 2013, though significant reductions in cryospheric influence are evident over large areas of northern Eurasia, especially during spring. Slightly negative LCrRE trends (indicating increased albedo) are evident over Antarctica, possibly due to increased snowfall frequency. LCrRE primarily depends on albedo contrast induced by snow and the propagation of surface-albedo anomalies to top-of-atmosphere energy fluxes. A slight variation in either of the two can cause a major impact on LCrRE estimates. Sensitivity analysis shows a secondary dependency of LCrRE on MODIS snow flag and global climatology derived using MODIS surface-albedo product, and changing either of those drops the LCrRE estimates by about $8 \%$ globally. Using different MODIS data quality flags (Q2 and Q4) does not have a significant effect on our LCrRE esti- 
mates. Using different radiative kernels can cause a variation of about 3-16\% in global LCrRE as compared to LCrRE with the CAM4 kernel, depending on the atmospheric attenuation present in each particular model due to cloud cover and aerosols.
For the consistency, we tried not use any partial-year data available at the time of analysis. Also, adding another year of the data (year 2014) would not have made any significant impact on the results. However, it would be beneficial to look into long-term trends (about 20-30 years) and comparison with previous research, with more MODIS data available in future. 


\section{Appendix A: Snow-covered albedo climatology by land} classification

Definitions for different land classes used in the MODIS MCD12C1 product are provided by the International Geosphere-Biosphere Programme (IGBP). Table A1 provide mean $(\mu)$ and standard deviation $(\sigma)$ of surface albedo for each land class type using Sect. 2.2 algorithm.
Table A1. Mean $(\mu)$ and standard deviation $(\sigma)$ of snow-covered surface albedo for different land class types. The averaging filter used to determine snow presence was based on both MODIS and NISE data sets of snow, and thus these averages are specific to the current study. MODIS provides surface albedo only over land, so albedo for water cannot be determined.

\begin{tabular}{lcc}
\hline Land class type & Mean $(\mu)$ & $\mathrm{SD}(\sigma)$ \\
\hline Water & $\mathrm{n} / \mathrm{a}^{*}$ & $\mathrm{n} / \mathrm{a}^{*}$ \\
Evergreen needleleaf forest & 0.30 & 0.008 \\
Evergreen broadleaf forest & 0.21 & 0.005 \\
Deciduous needleleaf forest & 0.33 & 0.024 \\
Deciduous broadleaf forest & 0.33 & 0.018 \\
Mixed forest & 0.29 & 0.013 \\
Closed shrublands & 0.42 & 0.023 \\
Open shrublands & 0.54 & 0.046 \\
Woody savannas & 0.40 & 0.025 \\
Savannas & 0.46 & 0.031 \\
Grasslands & 0.48 & 0.038 \\
Permanent wetlands & 0.41 & 0.027 \\
Croplands & 0.49 & 0.036 \\
Urban and built-up & 0.37 & 0.019 \\
Cropland/natural vegetation mosaic & 0.41 & 0.026 \\
Snow and ice & 0.72 & 0.033 \\
Barren or sparsely vegetated & 0.37 & 0.023 \\
\hline
\end{tabular}

$*_{\mathrm{n}} / \mathrm{a}=$ not applicable. 
Acknowledgements. This work was supported by NASA grant NNX13AN29G and NSF grant ARC-1253154.

Edited by: M. Tedesco

\section{References}

Bony, S., Colman, R., Kattsov, V. M., Allan, R. P., Bretherton, C. S., Dufresne, J.-L., Hall, A., Hallegatte, S., Holland, M. M., Ingram, W., Randall, D. A., Soden, B. J., Tselioudis, G., and Webb, M. J.: How Well Do We Understand and Evaluate Climate Change Feedback Processes?, J. Climate, 19, 3445-3482, doi:10.1175/JCLI3819.1, 2006.

Box, J. E., Fettweis, X., Stroeve, J. C., Tedesco, M., Hall, D. K., and Steffen, K.: Greenland ice sheet albedo feedback: thermodynamics and atmospheric drivers, The Cryosphere, 6, 821-839, doi:10.5194/tc-6-821-2012, 2012.

Brown, R. D. and Robinson, D. A.: Northern hemisphere spring snow cover variability and change over 1922-2010 including an assessment of uncertainty, The Cryosphere, 5, 219-229, doi:10.5194/tc-5-219-2011, 2011.

Cao, Y., Liang, S., Chen, X., and He, T.: Assessment of Sea Ice Albedo Radiative Forcing and Feedback over the Northern Hemisphere from 1982 to 2009 Using Satellite and Reanalysis Data, J. Climate, 28, 1248-1259, doi:10.1175/JCLI-D-14$00389.1,2015$.

Chapman, W. L. and Walsh, J. E.: A synthesis of Antarctic temperatures, J. Climate, 20, 4096-4117, doi:10.1175/JCLI4236.1, 2007.

Derksen, C., Brown, R., Mudryk, L., and Luojus, K.: Terrestrial Snow Cover [in Arctic Report Card 2014], http://www.arctic. noaa.gov/reportcard (last access: 25 October 2015), 2014.

Dery, S. J. and Brown, R. D.: Recent Northern Hemisphere snow cover extent trends and implications for the snow-albedo-feedback, Geophys. Res. Lett., 34, L22504, doi:10.1029/2007GL031474, 2007.

Ding, Q., Steig, E., Battisi, D., and Kuttel, M.: Winter warming in West Antarctica caused by central tropical Pacific warming, Nat. Geosci., 4, 398-403, doi:10.1038/ngeo1129, 2011.

Dumont, M., Brun, E., Picard, G., Michou, M., Libois, Q., Petit, J. R., Geyer, M., Morin, S., and Josse, B.: Contribution of lightabsorbing impurities in snow to Greenland's darkening since 2009, Nat. Geosci., 7, 509-512, doi:10.1038/ngeo2180, 2014.

Flanner, M. G., Shell, K. M., Barlage, M., Perovich, D. K., and Tschudi, M. A.: Radiative forcing and albedo feedback from the Northern Hemisphere cryosphere between 1979 and 2008, Nat. Geosci., 4, 151-155, doi:10.1038/ngeo1062, 2011.

Flato, G., Marotzke, J., Abiodun, B., Braconnot, P., Chou, S. C., Collins, W., Cox, P., Driouech, F., Emori, S., Eyring, V., Forest, C., Gleckler, P., Guilyardi, E., Jakob, C., Kattsov, V., Reason, C., and Rummukainen, M.: Evaluation of Climate Models, in: Climate Change 2013: The Physical Science Basis. Contribution of Working Group I to the Fifth Assessment Report of the Intergovernmental Panel on Climate Change, edited by: Stocker, T. F., Qin, D., Plattner, G.-K., Tignor, M., Allen, S. K., Boschung, J., Nauels, A., Xia, Y., Bex V., and Midgley, P. M., Cambridge University Press, Cambridge, UK and New York, NY, USA, 741866, doi:10.1017/CBO9781107415324.020, 2013.
Gardner, A. S., Moholdt, G., Cogley, J. G., Wouters, B., Arendt, A. A., Wahr, J., Berthier, E., Hock, R., Pfeffer, W. T., Kaser, G., Ligtenberg, S. R. M., Bolch, T., Sharp, M. J., Hagen, J. O., van den Broeke, M. R., and Paul, F.: A reconciled estimate of glacier contributions to sea level rise: 2003 to 2009, Science, 340, 852857, 2013.

Hudson, S. R.: Estimating the global radiative impact of the sea icealbedo feedback in the Arctic, J. Geophys. Res., 116, D16102, doi:10.1029/2011JD015804, 2011.

Kay, J. E., Holland, M. M., Bitz, C. M., Blanchard-Wrigglesworth, E., Gettelman, A., Conley, A., and Bailey, D.: The influence of local feedbacks and northward heat transport on the equilibrium Arctic climate response to increased greenhouse gas forcing, J. Climate, 25, 5433-5450, doi:10.1175/JCLI-D-11-00622.1, 2012.

Keegan, K. M., Albert, M. R., McConnell, J. R., and Baker, I.: Climate change and forest fires synergistically drive widespread melt events of the Greenland Ice Sheet, P. Natl. Acad. Sci., 111, 7964-7967, 2014.

Lyapustin, A., Wang, Y., Xiong, X., Meister, G., Platnick, S., Levy, R., Franz, B., Korkin, S., Hilker, T., Tucker, J., Hall, F., Sellers, P., Wu, A., and Angal, A.: Scientific impact of MODIS C5 calibration degradation and C6+ improvements, Atmos. Meas. Tech., 7, 4353-4365, doi:10.5194/amt-7-4353-2014, 2014.

Manabe, S. and Stouffer, R. J.: Multiple-century response of a coupled ocean-atmosphere model to an increase of atmospheric carbon dioxide, J. Climate, 7, 5-23, 1994.

Manabe, S., Spelman, M. J., and Stouffer, R. J.: Transient response of a coupled ocean-atmosphere model to gradual changes of atmospheric $\mathrm{CO}_{2}$, Part II: Seasonal response, J. Climate, 5, 105126, 1992.

Meehl, G. A. and Washington, W. M.: $\mathrm{CO}_{2}$ climate sensitivity and snow-sea-ice parameterization in an atmospheric GCM coupled to a mixed-layer ocean model, Climatic Change, 16, 283-306, 1990.

Miller, J. R. and Russell, G. L.: Projected impact of climatic change on the freshwater and salt budgets of the Arctic Ocean by a GCM, Geophys. Res. Lett., 27, 1183-1186, 2000.

Monaghan, A. J., Bromwich, D. H., Chapman, W., and Comiso, J.: Recent variability and trends of Antarctic near-surface temperature, J. Geophys. Res., 113, D04105, doi:10.1029/2007JD009094, 2008.

Moody, E. G., King, M. D., Schaaf, C. B., and Platnick, S.: MODISderived spatially complete surface albedo products: Spatial and temporal pixel distribution and zonal averages, J. Appl. Meteorol., 47, 2879-2894, doi:10.1175/2008JAMC1795.1, 2008.

Nolin, A., Armstrong, R. L., and Maslanik, J.: Near-Real-Time SSM/I-SSMIS EASE-Grid Daily Global Ice Concentration and Snow Extent, Version 4 (2001-2013), NASA DAAC at the National Snow and Ice Data Center, Boulder, Colorado, USA, 1998.

Perket, J., Flanner, M. G., and Kay, J. E.: Diagnosing shortwave cryosphere radiative effect and its 21 st century evolution in CESM, J. Geophys. Res.-Atmos., 119, 1356-1362, doi:10.1002/2013JD021139, 2014.

Picard, G., Domine, F., Krinner, G., Arnaud, L., and Lefebvre, E.: Inhibition of the positive snow-albedo feedback by precipitation in interior Antarctica, Nat. Clim. Change, 2, 795-798, 2012.

Pistone, K., Eisenman, I., and Ramanathan, V.: Observational determination of albedo decrease caused by vanishing Arc- 
tic sea ice, P. Natl. Acad. Sci. USA, 111, 3322-3326, doi:10.1073/pnas.1318201111, 2014.

Qu, X. and Hall, A.: Surface contribution to planetary albedo variability in cryosphere regions, J. Climate, 18, 5239-5252, 2005.

$\mathrm{Qu}, \mathrm{X}$. and Hall, A.: What controls the strength of snow-albedo feedback?, J. Climate, 20, 3971-3981, 2007.

Randall, D. A., Wood, R. A., Bony, S., Colman, R., Fichefet, T., Fyfe, J., Kattsov, V., Pitman, A., Shukla, J., Srinivasan, J., Stouffer, R. J., Sumi A., and Taylor, K. E.: Climate Models and Their Evaluation, in: Climate Change 2007: The Physical Science Basis, Contribution of Working Group I to the Fourth Assessment Report of the Intergovernmental Panel on Climate Change, edited by: Solomon, S., Qin, D., Manning, M., Chen, Z., Marquis, M., Averyt, K. B., Tignor, M., and Miller, H. L., Cambridge University Press, Cambridge, UK and New York, NY, USA, 2007.

Rignot, E., Velicogna, I., van den Broeke, M. R., Monaghan, A., and Lenaerts, J. T. M.: Acceleration of the contribution of the Greenland and Antarctic ice sheets to sea level rise, Geophys. Res. Lett., 38, L05503, doi:10.1029/2011GL046583, 2011.

Robinson, D. A. and Frei, A.: Seasonal variability of northern hemisphere snow extent using visible satellite data, Profess. Geogr., 51, 307-314, 2000.

Schaaf, C. B., Gao, F., Strahler, A. H., Lucht, W., Li, X. W., Tsang, T., Strugnell, N. C., Zhang, X. Y., Jin, Y. F., Muller, J. P., Lewis, P., Barnsley, M., Hobson, P., Disney, M., Roberts, G., Dunderdale, M., Doll, C., D'entremont, R. P., Hu, B. X., Liang, S. L., Privette, J. L., and Roy, D.: First operational BRDF, albedo nadir reflectance products from MODIS, Remote Sens. Environ., 83, 135-148, 2002.

Serreze, M. C., Holland, M. M., and Stroeve, J.: Perspectives on the arctic's shrinking sea-ice cover, Science, 315, 1533-1536, doi:10.1126/science.1139426, 2007.

Shell, K. M., Kiehl, J. T., and Shields, C. A.: Using the radiative kernel technique to calculate climate feedbacks in NCAR's community atmospheric model, J. Climate, 21, 2269-2282, 2008.
Soden, B. J., Held, I. M., Colman, R., Shell, K. M., Kiehl, J. T., and Shields, C. A.: Quantifying climate feedbacks using radiative kernels, J. Climate, 21, 3504-3520, doi:10.1175/2007JCLI2110.1, 2008.

Steig, E., Schneider, D. P., Rutherford, S. D., Mann, M., Comiso, J. C., and Shindell, D. T.: Warming of the Antarctic ice-sheet surface since the 1957 International Geophysical Year, Nature, 457, 459-462, doi:10.1038/nature07669, 2009.

Stroeve, J., Hamilton, L., Bitz, C. M., and BlanchardWrigglesworth, E.: Predicting September Sea Ice: Ensemble Skill of the SEARCH Sea Ice Outlook 2008-2013, Geophy. Res. Lett., 41, 2411-2418, doi:10.1002/2014GL059388, 2014.

Sun, J., Xiong, X., Angal, A., Chen, H., Wu, A., and Geng, X.: Time-dependent response versus scan angle for MODIS reflective solar bands, IEEE T. Geosci. Remote, 52.6, 3159-3174, 2014.

Tedesco, M., Box, J. E., Cappelen, J., Fettweis, X., Mote, T., van de Wal, R. S. W., Smeets, C. J. P. P., and Wahr, J.: Greenland Ice Sheet [in Arctic Report Card 2014], http://www.arctic.noaa.gov/ reportcard (last access: 25 October 2015), 2014.

Vaughan, D. G., Comiso, J. C., Allison, I., Carrasco, J., Kaser, G., Kwok, R., Mote, P., Murray, T., Paul, F., Ren, J., Rignot, E., Solomina, O., Steffen K., and Zhang, T.: Observations: Cryosphere, in: Climate Change 2013: The Physical Science Basis, Contribution of Working Group I to the Fifth Assessment Report of the Intergovernmental Panel on Climate Change, edited by: Stocker, T. F., Qin, D., Plattner, G.-K., Tignor, M., Allen, S. K., Boschung, J., Nauels, A., Xia, Y., Bex, V., and Midgley, P. M., Cambridge University Press, Cambridge, UK and New York, NY, USA, 317-382, doi:10.1017/CBO9781107415324.012, 2013.

Winton, M.: Surface albedo feedback estimates for the AR4 climate models, J. Climate, 19, 359-365, 2006. 